\title{
Evaluation of Restricted Antibiotics Utilisation in a Tertiary Care Teaching Hospital
}

\author{
Shiv Kumar, Ashish Kumar \\ Department of Pharmacy Practice, N.E.T. Pharmacy College, Raichur, Karnataka, INDIA.
}

\begin{abstract}
Aim: To assess the prescribing pattern of antibiotics among the inpatients of different wards of hospital, to assess the appropriateness of restricted antibiotics use associated with diagnosis and bacteriological finding, to assess the outcome of restricted antibiotics utilization. Materials and Methods: A prospective observational study was carried out on drug utilization pattern of restricted antibiotics. Case records of patients with restricted antibiotic therapy were reviewed and evaluated using descriptive statistics, mean and standard deviation. A total of 350 filled data entry forms were evaluated and analyzed. Results: Among the total 350 patients selected in which 189 male (54\%) and female $161(54 \%)$ were found. Total restricted antibiotics prescribed and administered through various routes are: PO 32 (9.14\%), IV $318(90.85 \%)$. Most drugs were given predominantly via IV route in inpatient wards. Different patients conditions like: Fever cases (15.71\%) seizure (9.71\%), AGE (5.71\%), LRTI $(1.14 \%)$, UTI $(0.57 \%)$, URTI $(1.14 \%)$, pneumonia $(13.42 \%)$, dengue $(0.85 \%)$, casualty $(2.28 \%)$, dysentery $(0.85 \%)$, bone fracture $(29.42 \%)$, surgery $(18.57 \%)$ etc were treated with restricted antibiotics. Conclusion: The study concludes that, the restricted antibiotics were mostly prescribed as empirical therapy in the study population. These drugs were predominantly administered by IV route for various infections and other pathological conditions. These large numbers of empirical prescriptions of restricted antibiotic shows the need to control of restricted antibiotic use.
\end{abstract}

Key words: Multi drug resistance, Antimicrobial, Restricted antibiotics, Alternative therapy, Antimicrobial resistance.

\section{INTRODUCTION}

Bacteria is a single celled organism which presents in variety of shapes, round, rodshaped, spiral, odd ball, round sphere,. It is an oldest living organism on earth. They don't produce offspring but reproduce by splitting in two. ${ }^{1}$ The use of antibacterial agent has given control of bacterial infections. Nowadays it is impossible to imagine health care that is not able to cope effectively with bacterial infection. Oncology, organ transplantation surgery and other medical disciplines would collapse without access to modern antibiotics. The success of antibiotics in the field of infectious disease for many decades has been led to very wide consumption of antimicrobial agents. Antibiotic have been used in large quantities as growth stimulants in husbanding and as prophylactic protection against plant pathogens. It has been said that "the world is immersed in a dilute solution of antibiotics". ${ }^{2}$
Antimicrobials are powerful medicines that fight microbial infections by killing the microorganisms or by keeping them away from copying themselves or reproducing. ${ }^{3}$

In 2010, India was the world's largest consumer of antibiotics for human health at $12.9 \times 10^{9}$ units (10.7 units per person). The next largest consumers were China at $10.0 \times 10^{9}$ units ( 7.5 units per person) and the US at $6.8 \times 10^{9}$ units (22.0 units per person). Seventy-six percent of the overall increase in global antibiotic consumption between 2000 and 2010 was attributable to BRICS countries, i.e., Brazil, Russia, India, China, and South Africa. In BRICS countries, 23\% of the increase in the retail antibiotic sales volume was attributable to India, and up to $57 \%$ of the increase in the hospital sector was attributable to China. The crude infectious disease mortality rate in India today is 416.75 per 100,000 persons (author calculations
DOI: 10.5530/ijopp.14.3.39

Address for correspondence: Dr. Shiv Kumar Professor and Head, Department of Pharmacy Practice, N.E.T Pharmacy College, Raichur-584 103, Karnataka, INDIA. Phone no: +919035663725 Email Id: shivkumarmatur@ gmail.com

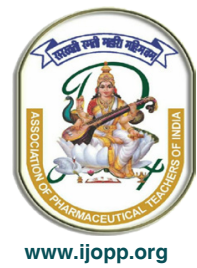


based on World Bank data and the Global Burden of Disease, 1990 and is twice the rate prevailing in the United States when antibiotics were introduced (roughly 200 per 100,000 persons). A mix of poor public health systems and hospital infection, high rates of infectious disease, inexpensive antibiotics, and rising incomes is coming together to increase prevalence of resistant pathogens and is increasing the burden of untreatable neonatal sepsis and health-care-associated infections. ${ }^{4}$ Antimicrobial resistance (AMR) poses a serious global threat of growing concern to human, animal, and environment health. This is due to the emergence, spread, and persistence of multidrug-resistant (MDR) bacteria or "superbugs. MDR bacteria exist across the animal, human, and environment triangle or niche and there is interlinked sharing of these pathogens in this triad. The plausible causes of "the global resist me" or AMR include excessive use of antibiotics in animals (food, pets, aquatic) and humans, antibiotics sold over-the-counter, increased international travel, poor sanitation/hygiene, and release of non-metabolized antibiotics or their residues into the environment through manure/feces. These factors contribute to genetic selection pressure for the emergence of MDR bacterial infections in the community. Recently, the global consumption of antimicrobials in livestock has indicated the hotspots of antibiotics use across the continents that will have economic and public health impacts in the years to come. ${ }^{5}$

\section{Problems associated with antibiotic use}

Lack of commitment and data, Unassured drug quality and irrational use, ${ }^{6}$ Poor prevention and control of infections. ${ }^{7}$ Prevention approach for antibiotic resistance: The national antimicrobial stewardship registry will report on an annual basis the quality of antibiotic use in hospitals. To restrict the use of parenteral antibiotics can be a good step towards antibiotic resistance prevention. Restriction of ceftazidime and ciprofloxacin in empirical and therapeutic uses. Rotation of antibiotics without favoring any one antibiotic. ${ }^{8}$ Due to inappropriate empirical antibiotics treatment, resistance increases. For physician, it is difficult to balance the early and aggressive treatment against conservative approach. Switching to narrower spectrum or stopping use of antibiotics when not needed, can be a good approach for antimicrobial resistance prevention. ${ }^{9}$

To ensure the prudent use of antimicrobials and reduce the risk of spreading resistance amongst antimicrobial agents, the ELMMB formulary of National Health Service United Kingdom has designated some antimicrobial agents as 'restricted drugs'. The Pharmacy Service will NOT supply antimicrobials from the restricted list unless prescribed for a formulary indication or there is documented evidence of Consultant Microbiologist approval in the medical notes and/or prescription chart. These antimicrobials may only be prescribed and supplied after approval from a Consultant Microbiologist. Pharmacists are required to confirm Microbiology approval or formulary indication before dispensing restricted antimicrobials.

- Restricted antimicrobials are:

- Amikacin

- Amphotericin B (Fungizone ${ }^{\circledR}$ and Liposomal)

- Aztreonam

- Ciprofloxacin*

- Ceftazidine

- Chloramphenicol IV/PO*

- Flucytosine

- Linezolid

- Meropenem*

- Nalidixic acid

- Piperacillin + Tazobactam*

- Sodium fusidate IV

- Tobramycin

- Cefuroxime

- Ertapenem

* May be prescribed for specific infections listed within the guidelines, or for patients on critical care without prior approval from a Consultant microbiologist. ${ }^{10}$

\section{MATERIALS AND METHODS}

\section{Subjects}

A prospective observational study was carried out for a period of 6 months from October 2019 to March 2020 after the approval from Institutional Ethics Committee of Navodaya Medical College Hospital and Research Centre, Raichur. A total of 350 patients were included in this study. The patients admitted as inpatient in various department of $\mathrm{NMCH}$ during study period and patient who are prescribed with at least one restricted antibiotic were included in this study. The pregnant, lactating women and outpatients were excluded from this study.

\section{Study design}

A well designed patient data entry form was developed and used for this study. The following information like patient demographic details (Name, age, gender, reason for hospitalization, duration of illness, smoking history, 
treatment chart etc) and culture report, sensitivity test for antibiotics were included. The patients were monitored for restricted antimicrobial prescribed, drugdrug interactions, administration information provided regarding each antimicrobial prescribed.

\section{Statistical analysis}

According to the Prevalence of sample size was determined using the prevalence value of Antibiotics used in Karnataka. By the following formula:

$\mathrm{n}=4 \mathrm{p}(1-\mathrm{p}) / \mathbf{L}^{2}$

- $\mathrm{n}$-Sample size

- L- $10 \%$ error

- P-Anticipated proportion (0.5392)

\section{RESULTS}

Table 1: Restricted Antibiotics Distribution among Different Sex Group ( $n=350$ ).

\begin{tabular}{ccc} 
Sex & Frequency & Percentage \\
\hline Male & 189 & $54 \%$ \\
Female & 161 & $46 \%$ \\
Total & 350 & \\
\hline
\end{tabular}

Table 2: Restricted Antibiotics Distribution among Different Age Group ( $n=350$ ).

\begin{tabular}{ccc} 
Age Group & Frequency & Percentage \\
\hline $\begin{array}{c}\text { Paediatric (0- 16 } \\
\text { years) }\end{array}$ & 43 & $12 \%$ \\
$\begin{array}{c}\text { Adult(17- } 60 \\
\text { years) }\end{array}$ & 255 & $73 \%$ \\
$\begin{array}{c}\text { Geriatric ( }>60 \\
\text { years ) }\end{array}$ & 52 & $15 \%$ \\
\hline
\end{tabular}

Table 3: Frequency of restricted antibiotics given through various routes $(n=350)$.

\begin{tabular}{ccc} 
& Frequency & Percentage \\
\hline PO & 32 & $9.14 \%$ \\
IV & 318 & $90.85 \%$ \\
\hline
\end{tabular}

\section{DISCUSSION}

A total of 350 patients prescribed with restricted antibiotics admitted as inpatients in various wards of the hospital were included for the study. Table 1 table represents the total distribution of male and female in
Table 4: Frequency of different restricted antibiotic prescribed for sample size population $(n=350)$.

\begin{tabular}{cccc} 
& $\begin{array}{c}\text { Restricted } \\
\text { antibiotic }\end{array}$ & $\begin{array}{c}\text { No. of } \\
\text { prescription }\end{array}$ & Percentage \\
\hline 1. & Amikacin & 103 & $29.42 \%$ \\
2. & Linezolid & 06 & $1.71 \%$ \\
3. & Cefuroxime & 74 & $21.41 \%$ \\
4. & Meropenem & 10 & $2.86 \%$ \\
5. & Piperacilin+ & 75 & $21.42 \%$ \\
& Tazobactam & & \\
6. & Ciprofloxacin & 82 & $23.42 \%$ \\
\hline
\end{tabular}

\begin{tabular}{|c|c|c|c|}
\hline Variables & $\begin{array}{l}\text { Response } \\
\text { pattern }\end{array}$ & $\begin{array}{l}\text { Frequency } \\
\qquad(n=350)\end{array}$ & Percentage \\
\hline \multirow{2}{*}{$\begin{array}{c}\text { Prescribing Pattern } \\
\text { of Restricted } \\
\text { Antimicrobials }\end{array}$} & Single & 337 & $96.28 \%$ \\
\hline & Multiple & 13 & $3.71 \%$ \\
\hline \multirow{3}{*}{$\begin{array}{l}\text { Information about } \\
\text { directions for } \\
\text { antimicrobial use }\end{array}$} & Complete & 70 & $20 \%$ \\
\hline & Incomplete & 200 & $57.14 \%$ \\
\hline & Not Mentioned & 80 & $22.85 \%$ \\
\hline $\begin{array}{c}\text { Antimicrobial } \\
\text { susceptibility tests }\end{array}$ & With Test & 13 & $3.71 \%$ \\
\hline $\begin{array}{l}\text { for prescribing } \\
\text { antimicrobials }\end{array}$ & Without Test & 337 & $96.28 \%$ \\
\hline \multirow{2}{*}{$\begin{array}{l}\text { Completion of } \\
\text { antimicrobial } \\
\text { course. }\end{array}$} & Yes & 328 & $93.71 \%$ \\
\hline & No & 22 & $6.28 \%$ \\
\hline \multirow{2}{*}{$\begin{array}{c}\text { Types of } \\
\text { antimicrobial } \\
\text { therapy }\end{array}$} & Mono Therapy & 117 & $33.42 \%$ \\
\hline & $\begin{array}{l}\text { Combination } \\
\text { Therapy }\end{array}$ & 233 & $66.57 \%$ \\
\hline
\end{tabular}

Table 6: Frequency of restricted antimicrobial used in different inpatient ward $(n=350)$.

\begin{tabular}{ccc} 
Department & $\begin{array}{c}\text { No. of restricted } \\
\text { antibiotics prescription }\end{array}$ & Percentage \\
\hline General medicine & 64 & $18.28 \%$ \\
Ortho & 103 & $29.42 \%$ \\
OBG & 45 & $12.85 \%$ \\
Surgery & 78 & $22.28 \%$ \\
PICU & 43 & $12.28 \%$ \\
Casualty & 08 & $0.22 \%$ \\
ENT & 09 & $2.57 \%$ \\
\hline
\end{tabular}

restricted antibiotics therapy. Total 350 patients were admitted in which 189 male (54\%) and female 161 (54\%) were found. it is lesser than supportive data of Varghese et al. ${ }^{11}$ Table 2 shows the distribution of antimicrobial use among various age group. paediatric group were given 43 restricted antimicrobials, our study also concluded that antimicrobials were found to be given more in adult group between $17-60$ years $(n=255,73 \%)$ which is almost similar Indian Journal of Pharmacy Practice, Vol 14, Issue 3, Jul-Sep, 2021 
to the data of Varghese et al. ${ }^{11}$ Table 3 represents total restricted antibiotics prescribed and administered through various routes are: PO 32 (9.14\%), IV 318 (90.85\%). Most drugs were given predominantly via IV route. Possible reasons for this may include; convenience in adjusting dose per age and weight for individual paediatrics and geriatrics, reduced palatability of the oral dose by the paediatric population. Nausea, diarrhoea and vomiting were the most common complaints of the patients suffering from surgery, fever, seizures and AGE, which constitute a significant proportion of the total diseases reported. Table 4 shows the extent of prescriptions of major class of restricted antimicrobial drugs. A total of 350 restricted antimicrobials were given, of which amikacin antibiotic constitute $29.42 \%(n=103)$ of the total antimicrobials prescribed followed by $82(23.42 \%)$ of ciprofloxacin, Piperacilin+ tazobactam $21.42 \%(n=75)$, cefuroxime $21.41 \%(n=74)$, meropenem $10(2.86 \%)$, and linezolid 6(1.61\%) were prescribed. Most of the cases due to enhanced antibacterial activity over a wide spectrum of bacterial species, less chances of treatment failure and easy availability in the area broad spectrum antibiotics were given. Our data ratio was higher than the Bizo PT et al. study. ${ }^{12}$ Table 5 illustrates the restricted antibiotics usage patterns. Single restricted antimicrobials used in highest frequency of 337 out of 350 (96.28\%). Multiple restricted antimicrobials prescribed were 13 (3.71\%). It suggests that one restricted antibiotic is almost sufficient for direct and empirical therapy. Whereas, multiple antimicrobials use increases the chance of MDR and side effects as well. Complete information was available for 70 prescriptions $(20 \%)$ where as incomplete information was with 200 prescriptions $(57.14 \%)$ and without mentioned information were $80(22.85 \%)$. This incomplete information leads to misuse of drug or administration error. This increases the irrationality of prescription. Only 13 (3.71\%) patients have undergone through antimicrobial susceptibility testing and 337 patients (96.28\%) had drug without susceptibility testing. It shows empirical therapy and irrational use of antibiotics. Our data shows lower value of susceptibility test compare to Varghese et al. study. ${ }^{11}$ Total 328 (93.71\%) out of total population had completed the course of therapy and 22 $(6.24 \%)$ did not complete the therapy (Table 5). Table 6 represents the highest no. of restricted antibiotic was given in orthopaedic ward 103(29.42\%), general medicine had 64 (18.24\%), surgery 78 (22.28\%), PICU 43 (12.28\%), OBG $45(12.85 \%)$, casualty $8(0.22 \%)$ and ENT 9 $(2.57 \%)$. In surgery ward most of the antibiotics were used for the purpose of chemoprophylaxis. Amikacin was mostly prescribed in orthopaedic ward and bone fracture condition. Similarities of data were observed of the study of Bizo et al. ${ }^{12}$ Table 7 illustrates the distribution of various diseases with antimicrobial use reported in inpatient ward. Fever cases $(n=55,15.71 \%)$ seizure $(n=34,9.71 \%)$, AGE $(n=20,5.71 \%)$, LRTI $(n=4,1.14 \%)$, UTI $(n=2,0.57 \%)$, URTI $(n=4,1.14 \%)$, pneumonia $(n=12,13.42 \%)$, dengue $(n=3,0.85 \%)$, casualty $(n=8$, $2.28 \%)$, other diseases $(n=11,3.14 \%)$, bone fracture 103 $(29.42 \%)$, surgery $65(18.57 \%)$ etc. Fever and AGE are few of the most common frequent ailments suffered by paediatric population and may be due to food, and water contamination or air borne sources. Respiratory diseases like LRTI and URTI are also common in the area which may be because of occupation of most of the population being agriculture, or due to air pollution. Occurrence of more UTI cases suggests the unhygienic practices. Table 8 illustrates details of concomitant drugs prescribed along with restricted antibiotics. Non-restricted antibiotics 149 (16.97\%), Proton Pump Inhibitors 125 (14.23\%), Anti-hypertensive 94 (10.70\%), H Receptor Blocker 95(10.82\%), Antipyretics 58 (6.60\%), NSAIDS 42 (4.78\%), Anti Hyperlipidemic 41 (4.66\%), Antiasthmatic 40 (4.55\%), Cardiovascular drugs 36 (4.10\%), Calcium 103 (11.73\%), Trypsin- chemo trypsin 95 (10.82\%). Concomitant drug such as antibiotics were prescribed to avoid hospitalized infections and antihypertensive is according to past medical history like hypertension. Other drugs were prescribed for symptomatic treatment. WHO core drug prescribing indicators measure the performance of health care providers in several key dimensions, related to the appropriate use of drugs. 5 prescribing indicators are given by the World Health Organization. First prescribing indicator is average no. of drugs per prescription which measures the extent of polypharmacy. WHO standard value is 1.6-1.8 but obtained study value was 3.50 which shows polypharmacy. Previous study of Mahlli EL A.A. ${ }^{13}$ is similar to obtained value. Percentage of drugs prescribed by generic name was obtained $12.45 \%$, which is very much lower than standard value of $100 \%$. Percentage of encounters with an antibiotic prescribed was $100 \%$ because this is a study of antibiotics prescriptions. Percentage of encounters with an injection prescribed was found much higher $(90.85 \%)$ than standard value of $13.4-24.1 \%$. percentage of drugs prescribed from essential drug list was $81 \%$ compared to $100 \%$ of standard value. Percentage of encounters with an injection prescribed was found much higher $(90.85 \%)$ than standard value of $13.4-24.1 \%$. percentage of drugs prescribed from essential drug list was $81 \%$ compared to $100 \%$ of standard value (Table 9)..$^{44,15}$ Average duration of therapy with the antimicrobials are shown in the Table 10 with average duration of therapy of amikacin 8.5, meropenem 4, piperacillin tazobactam 5.7, cefuroxime 3 , linezolid 2.3, ciprofloxacin 3.3 the overall average duration was found to be $3.6( \pm 1.4)$ days. This complies with the 
Table 7: Distribution of diseases encountered ( $n=350)$.

\begin{tabular}{ccc}
\hline Diseases & Frequency & Percentage \\
\hline Fever under evaluation & 55 & $15.71 \%$ \\
Seizure & 34 & $9.71 \%$ \\
AGE & 20 & $5.71 \%$ \\
LRTI & 04 & $1.14 \%$ \\
UTI & 02 & $0.57 \%$ \\
URTI & 4 & $1.14 \%$ \\
Pneumonia & 12 & $3.42 \%$ \\
Dengue fever & 3 & $0.85 \%$ \\
Casualty & 08 & $2.28 \%$ \\
Anaemia & 3 & $0.85 \%$ \\
Bronchiolitis & 2 & $0.57 \%$ \\
Hepatitis & 2 & $0.57 \%$ \\
Typhoid & 2 & $0.57 \%$ \\
Bone fracture & 103 & $29.42 \%$ \\
Surgery & 65 & $18.57 \%$ \\
Ear disorder & 09 & $2.57 \%$ \\
Diabetes & 05 & $1.42 \%$ \\
Cellulites & 06 & $1.71 \%$ \\
Other diseases & $3.14 \%$ \\
\hline & & \\
\hline & 05 & 0.5 \\
\hline
\end{tabular}

\section{Table 8: Concomitant Drugs prescribed ( $n=878)$.}

\begin{tabular}{cccc} 
SI.No & Drugs & $\begin{array}{c}\text { No of } \\
\text { patients }\end{array}$ & Percentage (\%) \\
\hline 1 & $\begin{array}{c}\text { Non- } \\
\text { restrictedAntibiotics }\end{array}$ & 149 & 16.97 \\
2 & $\begin{array}{c}\text { Proton Pump } \\
\text { Inhibitors }\end{array}$ & 125 & 14.23 \\
\hline 3 & Anti hypertensives & 94 & 10.70 \\
4 & H2 Receptor Blocker & 95 & 10.82 \\
5 & Antipyretics & 58 & 6.60 \\
6 & NSAIDs & 42 & 4.78 \\
7 & Anti Hyperlipidemic & 41 & 4.66 \\
8 & Antiasthmatic & 40 & 4.55 \\
9 & Cardiovascular drugs & 36 & 4.10 \\
10. & Calcium & 103 & 11.73 \\
11. & Trypsin- chymo & 95 & 10.82 \\
& trypsin & & \\
\hline & & & \\
\hline
\end{tabular}

guidelines as minimum duration of the antimicrobial therapy for common infectious diseases should be 3 days which could extend to 5 or 7 or 14 day depending upon

\begin{tabular}{|c|c|c|c|}
\hline S.no. & Indicators & Study value & $\begin{array}{l}\text { Standard } \\
\text { value }\end{array}$ \\
\hline 1 & $\begin{array}{c}\text { Average Number Of } \\
\text { Drugs Per Prescription }\end{array}$ & 3.50 & $1.6-1.8$ \\
\hline 2 & $\begin{array}{l}\text { Percentage Of Drugs } \\
\text { Prescribed By Generic } \\
\text { Name }\end{array}$ & 12.45 & $100 \%$ \\
\hline 3 & $\begin{array}{l}\text { Percentage Of } \\
\text { Encounters With An } \\
\text { Antibiotic Prescribed }\end{array}$ & $100 \%$ & $20.26-26.8 \%$ \\
\hline 4 & $\begin{array}{c}\text { Percentage of } \\
\text { encounters with an } \\
\text { injection prescribed }\end{array}$ & $90.85 \%$ & $13.4-24.1 \%$ \\
\hline 5 & $\begin{array}{l}\text { Percentage Of Drugs } \\
\text { Prescribed From } \\
\text { Essential Druq List }\end{array}$ & $81 \%$ & $100 \%$ \\
\hline
\end{tabular}

Table 10: Average duration of restricted antimicrobial therapy.

\begin{tabular}{cc}
$\begin{array}{c}\text { Antimicrobial } \\
\text { Agents }\end{array}$ & $\begin{array}{c}\text { Average Number of Days } \\
\text { Administered [Mean } \pm(\text { SD)] }\end{array}$ \\
\hline Amikacin & $8.5( \pm 1.8)$ \\
Meropenem & $4( \pm 1.3)$ \\
Piperacillin/ & $5.7( \pm 2.7)$ \\
tazobactam & $3.0( \pm 1.4)$ \\
Cefuroxime & $2.3( \pm 1.5)$ \\
Linezolid & $3.3( \pm 1.6)$ \\
Ciprofloxacin & \\
\hline
\end{tabular}

the seriousness of the condition. The results synchronize with that of the study conducted by Bhullar et al.'

\section{CONCLUSION}

The study concludes that, the restricted antibiotics were mostly prescribed as empirical therapy in the study population. These drugs were predominantly administered by IV route for various infections and other pathological conditions. Over use of restricted antibiotics is a special factor for antibiotic resistance. These large numbers of empirical prescriptions of restricted antibiotic shows the need to control of restricted antibiotic use. A stewardship program is very necessary to implement in the hospital. Establishment of drug formularies in hospitals and the involvement of the clinical pharmacist in order to ensure rational antibiotic therapy may improve the quality of patient care and reduce the cost of therapy. ${ }^{16,17}$ The most common interventions were found to be need of rapid laboratory testing, guidelines generation for restriction of drugs, need to review prescription by the clinical pharmacist.

Indian Journal of Pharmacy Practice, Vol 14, Issue 3, Jul-Sep, 2021 


\section{ACKNOWLEDGEMENT}

I express our sincere thanks to Shri.S.R.Reddy, M.Pharm Chairman, Navodaya Educational Trust, Dr. Ashok Mahendraker, Medical Superintendent, NMCH and RC, Raichur and Dr. H. Doddayya, Principal, N.E.T Pharmacy College, Raichur, Dr. Shankarappa, HOD of General Medicine Department NMCH and RC, Dr. K B Phuleker, HOD of Surgery Department NMCH and RC, Dr. Arun, HOD of Orthopedic Department NMCH and RC, Dr. Rita D, HOD of OBG Department NMCH and RC, for their valuable guidance and suggestions throughout my research work.

\section{CONFLICT OF INTEREST}

The authors declare no conflict of interest.

\section{ABBREVIATIONS}

HTN: Hypertension; ICU: Intensive Care Unit; ICCU: Intensive Cardiac Care Unit; INRUD: International Network for Rational Use of Drugs; ADR's: Adverse Drug reactions; AMR: antimicrobial resistance; MRSA: methicillin resistance Staphylococcus aureus; NSAID: NonSteroidal Anti-Inflammatory Drug.

\section{SUMMARY}

Based on prescription details it observed that number of male patients (54\%) were more than females $(46 \%)$. Most prescribed antimicrobials categories were Beta lactam antibiotics, followed by aminoglycosides, macrolides, oxazolidinones, etc. Ceftriaxone was the most encountered antibiotic followed by amoxicillin/ clavulanate, piperacillin/tazobactam and azithromycin. Whereas in restricted category antibiotics amikacin, piperacillin tazobactam, cefroxime, ciprofloxacin were mostly prescribed. $90 \%$ of IV routes were preferred while $10 \%$ was oral route. The cases were encountered with multiple antimicrobial therapy and no laboratory sensitivity test were relayed on to ensure the use of any antimicrobials. Higher number of prescriptions with amikacin, ciprofloxacinand piperacilin/tazobactam was found. Amikacin was mostly prescribed in orthopedic department as post-surgery therapy. Prescription of single restricted antibiotics was more in number while multiple restricted antibiotic prescriptions along with other nonrestricted or restricted antibiotics was less. Complete information about direction for antibacterial use were given in less no. of prescriptions while incomplete information or without any information prescriptions were in large number. Minimal numbers of antimicrobial susceptibilities tests were performed for prescribing restricted antimicrobials. Overall prescriptions were based upon empirical therapy. Orthopedic, surgery and general medicine had more restricted antibiotics prescription than other wards. Rationality of prescription was found minimal based on the accurate diagnosis, proper prescribing, correct dispensing and patient adherence. Distributions of diseases in selected population were evaluated in which bone fracture, fever, surgery, seizures, AGE, pneumonia were mostly found. Majority of concomitant drugs evaluated were non restricted antibiotics, proton pump inhibitors, anti-hypertensive and others along with restricted antibiotics prescriptions. Drug interactions and poly pharmacy were also evaluated. Only $12.45 \%$ and $81 \%$ of the drugs were prescribed by generic name and from essential drug list respectively. $53.5 \%$ of the prescription collected was having major polypharmacy of which $1.31 \%$ was identified as hyperpolypharmacy. The prospective observational study assesses the drug utilization and prescribing patterns in inpatient department in a tertiary care teaching hospital. By conducting such, studies, we can know about the patterns and quality of use of medicines, the determinants of drug use and their outcomes. WHO drug use indicators are highly standardized forms for inclusion in drug utilization studies. Drug utilization studies increases the awareness among physicians about essential drug concept and use of standard treatment guidelines to encourage the rational drug utilization and reduce the economic burden and provide quality treatment to patients.

\section{REFERENCES}

1. Mayers L, Douglas S, et al. Antimicrobial Drug Resistance. Springer International Publication. 2009;1(2):978-4.

2. Ola S, etal. Antibiotics and Antibiotic resistance. Wiley Publication. 2011;1(3):978-2.

3. Medilineplus US. National Library of Medicine, Rockville Pike, Bethesda, U.S. Department of Health and Human Services National Institutes of Health. 2019.

4. Laxminarayan R, Chaudhury RR. Antibiotic Resistance in India: Drivers and Opportunities for Action. PLoS Med. 2016;13(3):1-7.

5. Aslam B, Wang W, Arshad MI, Khurshid M, Muzammil S, Rasool MH, et al. Antibiotic resistance: A rundown of a global crisis. Infect Drug Resist. 2018;11:1645-58.

6. Gould IM. A review of the role of antibiotic policies in the control of antibiotic resistance, J.Antimicrobi. Chemother.April 1999; 43(4):459-65.

7. Leung E, Weil DE, Raviglione M, Nakatani H. WHO policy package to combat antimicrobial resistance. Bulletin of the World Health Organization. 2011;89:39092.

8. Gruson D, Hilbert G, Vargas F, Valentino R, Bebear C, et al. Rotation and restricted use of antibiotics in a medical intensive care unit. Am J Respir Crit Care Med. 2000;162(3):1-18.

9. Bhullar SH, Shaikh FAR, Deepak R, Poddutoor PK, Chirla D. Antimicrobial Justification form for Restricting Antibiotic Use in a Pediatric Intensive Care Unit. Indian Pediatrics. 2016;53(4):304-6.

10. Restricted antibiotic list. www.elmmb.nhs.uk/specialist-formulary/secondarycare-guidelines-for-management-of-infections-in-adults/restricted-antibiotic-list, east Lancashire health economy medicines management board.

11. Varghese TS, Surendran L, Antony C, Selvaraj H, Varghese E, et al. A Prospective Observational Study on Drug Utilisation Pattern of Restricted Antibiotics: Colistin, Teicoplanin and Tigecycline in a Tertiary Care Hospital. Indian Journal of Pharmacy Practice. 2017;10(3):216-21. 
12. Bizo PT, Dumitras D, Popa A. Evaluation of restricted antibiotic use in a hospital in Romania. Int J Clin Pharm. 2015;37(3):452-6.

13. Mahalli EAA. WHO/ INURD drug prescribing indicators at primary health care centers in Eastern province, Saudi Arabia. Eastern Mediterranean Health Journal. 2012;11(18):1091- 6.

14. Isah A, Degnam-Ross D, Quick J, Laing R, et al. WHO. The development of standard values for the WHO drug use prescribing indicators, essential medicines and policy department. 2012.
15. WHO, The pursuit of responsible use of medicines sharing and learning from country experiences. 2012;78(3):1-2.

16. Thuong M, Shortgen F, Zazempa V, Girou E, Soussy CJ, et al. Appropriate use of restricted antimicrobial agents in hospitals: The importance of empirical therapy and assisted re-evaluation. J Antimicrobi Chemother. 2000;46(3):5018.

17. Bizo PT, Dumitras D, Popa A. Evaluation of restricted antibiotic use in a hospital in Romania. Int J Clin Pharm. 2015;37(3):452-6. 